\title{
PENDAMPINGAN PAMSIMAS DALAM PENERAPAN TEKNOLOGI TEPAT GUNA MIKRO FILTRASI DESA JUNWANGI SIDOARJO
}

\author{
Yitno Utomo ${ }^{1)}$, Dwi Arwanto ${ }^{2)}$, Arif Rachman Hakiki ${ }^{3)}$, M. Lutfi Riansyah ${ }^{4)}$ \\ ${ }^{1}$ Teknik Industri, Universitas PGRI Adi Buana Surabaya \\ 2,3,4 Teknik Lingkungan, Universitas PGRI Adi Buana Surabaya \\ email: ${ }^{1}$ yitno@unipasby.ac.id, ${ }^{2}$ dwi.asry@gmail.com, \\ ${ }^{3}$ arifhakiki@gmail.com,${ }^{4}$ lutfiryansah@gmail.com
}

\begin{abstract}
Abstrak
Pengabdian kepada masyarakat Desa Junwangi Kecamatan Krian Kabupaten Sidoarjo yang merupakan bentuk kewajiban mahasiswa diluar kampus dapat diterapkan dengan baik melalui pendampingan Teknologi Tepat Guna. Pelaksanaan kegiatan ini dengan tujuan memberikan pendampingan pengelolaan Pamsimas "Tirto Yoso" dalam hal proses maintenance mikro filtrasi serta upaya edukasi masyarakat terhadap fungsi penggunaan air bersih dari hasil sumur atau air tanah. Metode pelaksanaan yang digunakan berupa tahapan; Sosialisasi edukasi masyarakat, pelatihan perawatan dan pemberian fasilitas pendukung. Kegiatan diikuti oleh ketiga stakeholder yaitu ; pengelola pamsimas, pelanggan air dan karang taruna. Hasil pembahasan dari kegiatan ini yaitu ; (1) Sosialisasi tentang kajian TTG pada mikro filter sebagai alat peningkatan kualitas air kepada stakeholder yaitu Pamsimas, pelanggan dan karang taruna. (2) Perawatan (maintenance) pada peralatan pembersih air yaitu pembongkaran housing filter dan tabung FRP. (3) Pemberian fasilitas pendukung berupa alat sedimen poly propilen yang bertujuan untuk menjernihkan air dari kandungan lumpur, pasir dan tanah
\end{abstract}

Keywords: Teknologi Tepat Guna, Mikro Filtrasi, Air Bersih, Desa Junwangi

\begin{abstract}
The service to the people of Junwangi Village, Krian District, Sidoarjo Regency, which is the obligation of students outside the campus, can be implemented properly through Appropriate Technology assistance. This activity is carried out with the aim of providing assistance in the management of Pamsimas "Tirto Yoso" in the process of maintaining micro-filtration as well as efforts to educate the public on the function of using clean water from wells or ground water. The implementation method used in stages; Socialization of community education, maintenance training and provision of supporting facilities. The activities followed by the three stakeholders, namely; pamsimas managers, water customers and youth organizations. The results of the discussion of this activity are; (1) Dissemination of the TTG study on the micro filter as a means of improving air quality to stakeholders, namely Pamsimas, customers and youth organizations. (2) Maintenance of water cleaning equipment, namely dismantling of the filter housing and FRP tube. (3) Provision of supporting facilities in the form of a poly propylene sediment device aimed at purifying the air from the content of mud, sand and soil.
\end{abstract}

Keywords: Appropriate Technology, Micro Filtration, Clean Water, Junwangi Village 


\section{PENDAhuluan}

Kuliah Kerja Nyata adalah bagian dari sebuah pengabdian kepada masyarakat yang merupakan bentuk pengamalan ilmu pengetahuan, teknologi dan seni dalam upaya memecahkan permasalahan serta menanggulangi secara pragmatis. Dengan kata lain KKN-PPM membantu dan memotivasi masyarakat dengan melaksanakan pengamalan ilmu pengetahuan, teknologi dan seni. Dengan pengamalan ilmu pengetahuan, teknologi dan seni akan menambah pengalaman mahasiswa secara lengkap tentang kehidupan di masyarakat.

Air merupakan sumber daya alam yang mempunyai fungsi sangat penting bagi kehidupan manusia dan mahluk hidup lainnya serta sebagai modal dasar dalam pembangunan (Waluyo, 2009). Dengan perannya yang sangat penting, hendaknya dilakukan suatu perencanaan yang tepat agar ketersediaan air bersih dapat terpenuhi. Program Pamsimas yang gagas oleh Pemerintah Daerah telah di jalankan di Desa Junwangi dimana telah beroperasi dari bulan Februari 2020 hingga saat ini dan sudah memeliki lebih dari 200 pelanggan. Kebutuhan air bersih juga menjadi bagian yang sangat penting, seperti dalam penelitian Utomo (2018) bahwa untuk PDAM Surya Sembada Surabaya saja sudah menerapkan aplikasi teknologi dalam bentuk penilaian TAM (Technology Acceptance Model) untuk mengukur kepuasan pelanggannya.

Dalam aliran air tanah, mineral-mineral dapat larut dan terbawa sehingga mengubah kualitas air tersebut. Pada umumnya air tanahatau air sumur mempunyai tingkat kesadahan yang tinggi. Hal ini terjadi karena air tanah mengalami kontak dengan batuan kapur yang ada pada lapisan tanah yang dilalui air. Masalah lain yang timbuldari air tanah adalah kandungan LogamBesi (Fe) dan Mangan (Mn). Adanya kandungan Fe dan Mn dalam air menyebabkan warna air tersebut berubah menjadi kuning-coklat beberapa saat kontak dengan udara (Purwoto, S., 2016)

Pengolahan air memang menjadi prioritas di desa Junwangi kecamatan Krian Kabupaten Sidoarjo, begitu juga banyak penelitian yang mengolah air dengan menggunakan teknologi Tekno Membran Reverse Osmosis (Ro) seperti yang dilakukan Nurhayati (2006) mampu mengubah air payau melalui proses kimiawi. Selain itu kajian teori juga terdapat pada bukunya Masduqi (2012) bahwa filtrasi adalah suatu proses pemisahan zat padat dari fluida (cairan maupun gas) yang membawanya menggunakan suatu media berpori atau bahan berpori untuk menghilangkan sebanyak mungkin zat padat halus yang tersuspensi dan koloid.

Penting juga peran Ferrolite adalah media filter yang digunakan untuk menurunkan atau menghilangkan kandungan zat besi yang terlalu tinggi dalam air, dan ferrolit emerupakan suatu jawaban untuk menghilangkan kandungan zat besi dan mangan yang terdapat dalam air sumur. (Putra, Made, 2015).

Air dari sumber alami biasanya mengandung banyak padatan terlarut dan tersuspensi. Partikel tersuspensi yang besar seperti pasir yang dinamakan partikel diskrit dapat diolah dengan sedimentasi atau filtrasi. Pertikel tersuspensi yang lebih kecil yang tidak mudah diendapkan tersebut disebut koloid. Partikel koloid dapat diolah dengan penambahan bahan kimia kemudian diendapkan pada sedimentasi dan filter (Syed, 2000).

Kinerja resin merupakan proses terjadinya pertukaran ion (Ion- Exchanger) antara kationanion dalam resin dengan anion-kation yang terdapat pada larutan yang diperlakukan. Dalam proses demineralisasi, maka sebagai contoh ; kation $\mathrm{Na}+$ dan anion Cldisisihkan dari air dan solid resin melepas ion $\mathrm{H}+$ untuk ditukar dengan ion $\mathrm{Na}+$, serta $\mathrm{OH}$ - ditukar dengan Cldari air sehingga kandungan $\mathrm{Na}+$ dan $\mathrm{Cl}$ dalam air menjadi berkurang atau hilang (Montgomery, 2005). Bahwa untuk menghasilkan air jernih dari air sungai yang keruh jika dilakukan pengolahan (treatment) menggunakan koagulan dilanjutkan dengan filtrasi, kemudian absorben zeolit dan MGS, filter pasir silika dan diakhiri menggunakan resin sintetis kation dan resin sintetis anion (Purwoto, S, 2015)

Problem pertama sebagai permasalahan pada bak penampungan air di Pamsimas Tirto Yoso ini dapat disebutkan bahwa hasil laboratorium, menunjukan bahwa : 
Gambar 1. Peta Wilayah Desa Junwangi

Tabel 1. Hasil Laboratorium Air

\begin{tabular}{ll}
\hline \multicolumn{1}{c}{ Bak Penampung } & \multicolumn{1}{c}{ Parameter } \\
\hline Logam besi & $1,0688 \mathrm{mg} / \mathrm{L}$ \\
Logam mangan & $1,0078 \mathrm{mg} / \mathrm{L}$ \\
Kekeruhan & $9,0 \mathrm{mg} / \mathrm{L}$ \\
\hline \multicolumn{1}{c}{ Rumah warga } & \multicolumn{1}{c}{ Hasil Lab. } \\
\hline \multicolumn{1}{c}{ Parameter } & $1,0685 \mathrm{mg} / \mathrm{L}$ \\
Logam besi & $1,0070 \mathrm{mg} / \mathrm{L}$ \\
Logam mangan & $188 \mathrm{mg} / \mathrm{L}$ \\
Kekeruhan &
\end{tabular}

Tujuan dilaksanakan pengabdian pada masyarakat melalui KKN-PPM 2020/2021 ini adalah memberikan pendampingan pengelolaan Pamsimas "Tirto Yoso" dalam hal proses maintenance mikro filtrasi serta upaya edukasi masyarakat terhadap fungsi penggunaan air bersih dari hasil sumur atau air tanah.

\section{METODE PELAKSANAAN}

Pelaksanaan kegiatan ini dilakukan di desa Junwangi Kecamatan Krian Kabupaten Sidoarjo, mata pencaharian penduduk yang paling banyak sebagai karyawan di sebuah perusahaan yang capainya hingga $30 \%$ serta kegiatan yang lainnya juga berdagang serta ada sebagai yang pertanian. Hal ini memungkinkan penduduka yang berjumlah sekitar 4.962 orang, menempati wilayah sebesar 160.007.000 Ha.
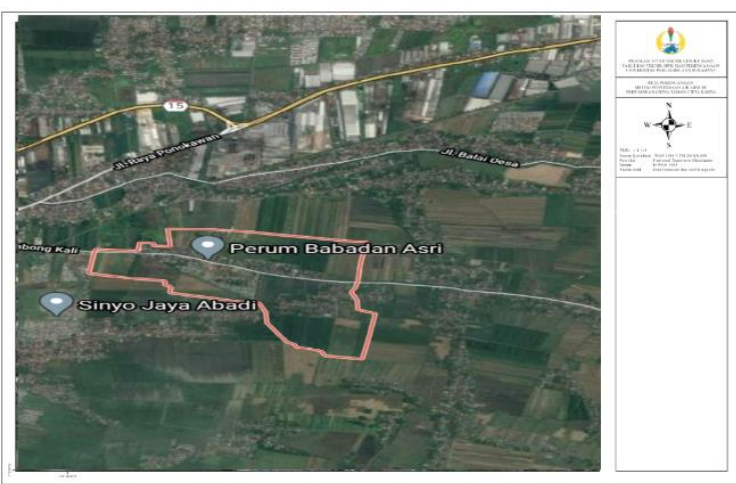

Metode pelaksanaan kegiatan, menggunakan kajian-kajian sebagai berikut :

1. Sosialisasi edukasi masyarakat

2. Pelatihan Maintenance (Perawatan alat)

3. Pemberian fasilitas pendukung

Dari ketiga tahapan kegiatan tersebut diharapkan Pamsimas Tirto Yoso setelah pelaksanaan kegiatan KKN ini memiliki kemadirian dalam proses pengelolaan, baik berupa keuangan secara ekonomi meningkat pendapatan pamsimas, juga seacra manfaat yaitu masyarakat mendapatkan air bersih.

\section{HASIL DAN PEMBAHASAN}

Hasil pelaksanaan kegiatan KKN-PPM 2020/2021 dalam tatanan perubahan baru masa Pandemi covid-19, dapat dilihat kegiatan sebagai berikut :

\section{a. Pembukaan kegiatan}

Pada pembukaan awal kegiatan ini dilakukan di balai desa Junwangi yang dilakukan dengan rapat terbatas seperti kegiatan FGD (Focus Group Discussion), karena harus mematuhi protocol kesehatan, yang kebetulan juga di hadiri oleh Kepala desa Junwangi, dengan kegiatan awal menyampaikan rencana kegiatan selama 1 bulan di desa ini.

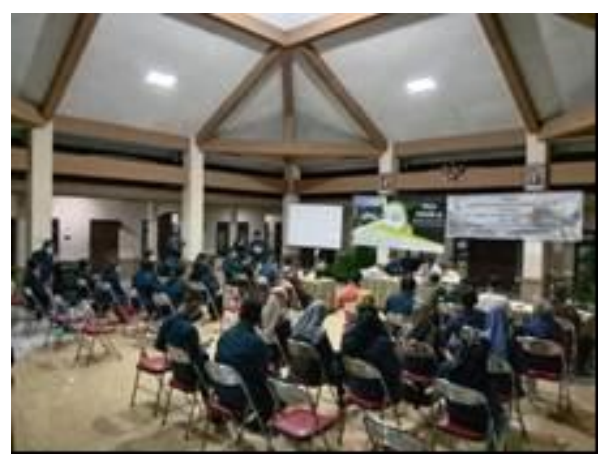

Gambar 2. Pembukaan Rapat Terbatas (FGD)

Pembukaan ini setidaknya dihadiri seluruh anggota KKN-PPM untuk DPL 34 sejumlah 40 
orang mahasiswa beserta undangan perangkat desa juga kelompok Pamsimas serta karang taruna.

\section{b. Sosialisasi Penerapan TTG}

Bentuk sosialisasi penerapan Teknologi Tepat Guna (TTG) pada kegiatan ini dilakukan pada stakeholder dalam hal ini masyarakat dan pengelola air bersih yaitu Pamsimas "Tirto Yoso." Kegiatan yang dimaksud adalah memberikan penyuluhan tentang nilai kelayakan air bersih yang sedang di kelola oleh Pamsimas ini, dan tidak boleh ragu terhadap hasil air bersih tersebut.

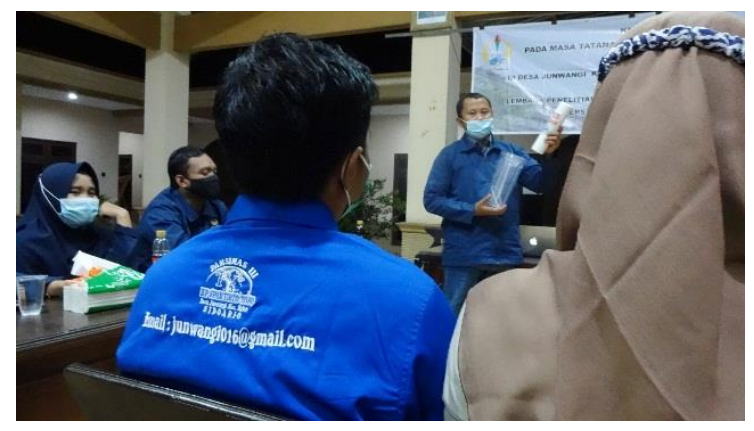

Gambar 3. Pelaksanaan Sosialisasi

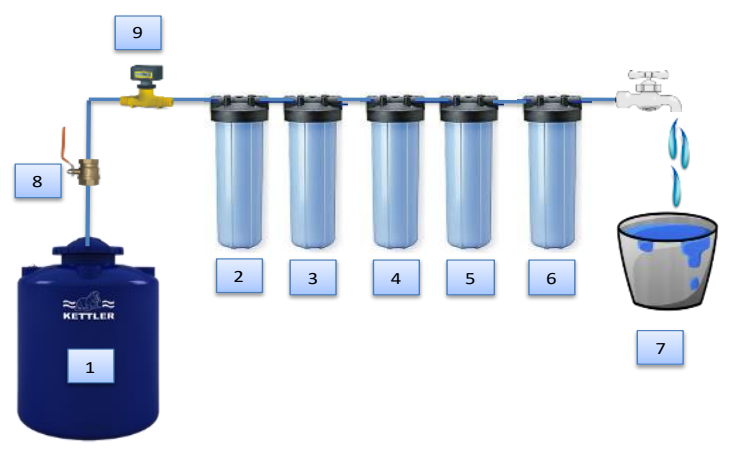

Gambar 4. Reaktor Mikro Filtrasi

Keterangan dari gambar diatas dapat dijelaskan berdasarkan nomer urutannya sebagai berikut : (1) Tandon air baku (2) Housing filter dengan media Sedimen poly propilen $03 \mu$ (3) Housing filter dengan media Ferrolite (4) Housing filter dengan media Manganse Green sand (5) Housing filter dengan media Resin penukar ion (6) Housing filter dengan media Sedimen poly propilen $05 \mu$
(7) Bak penampunghasil treatment (7) Stop kran Flow meter (pengatur laju alir)

Proses pengolahan air Pamsimas (running reaktor) ini dimulai dengan menampung bahan baku ke dalam tandon, kemudian di pompa ke atas melewati flow meter untuk mendapatkan laju alir yang ditentukan dan menuju treatment 2 ke housing (a) filter Sedimen poly propilen $03 \mu$. Lanjut ke treatment 3 pada housing (b) filter yang berisi ferrolite. Lanjut ke treatment 4 pada housing (c) filter yang berisi Mangan Green Sand. Lanjut ke treatment 5 pada housing (d) filter yang berisi Resin Penukar Ion. Lanjut ke treatment 6 pada housing (e) filter yang berisi Sedimen poly propilen $05 \mu$. Treatment di lakukan secara kontinue sehingga diperoleh hasil air yang baik.

\section{c. Pelatihan Maintenance (Perawatan)}

Pada Program Utama kegiatan KKN khususnya DPL KKN 34 Prodi Tekning Lingkungan mempunyai program utama yaitu Pamsimas yang di miliki desa junwangi, yang di beri nama "Pamsimas Tirto Yoso ". Dalam program Pamsimas ini menjadi program utama karena salah satu dalam tatanan baru Covid-19 yang di wajubkan dalam Protokol Kesehatan adalah salah satunya mencuci tangan dengan bersih. Program Pamsimas berupaya menyediakan air bersih ke masyarakat khususnya RW 05 Perumahan Babadan Asri. Dalam Program Utama ini mahasiswa KKN terlibat dalah majalankan/mengoperasikan serta melakukan perawatan Filtrasi TT (Teknologi Tepat Guna).

1) Perawatan Filter

Melakukan pencucian media filter pada Housing dan media tabung filter.

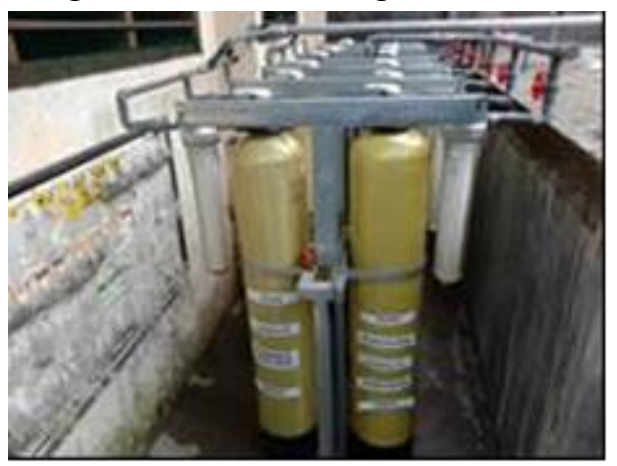

Gambar 5. Pencucian Housing Filter 


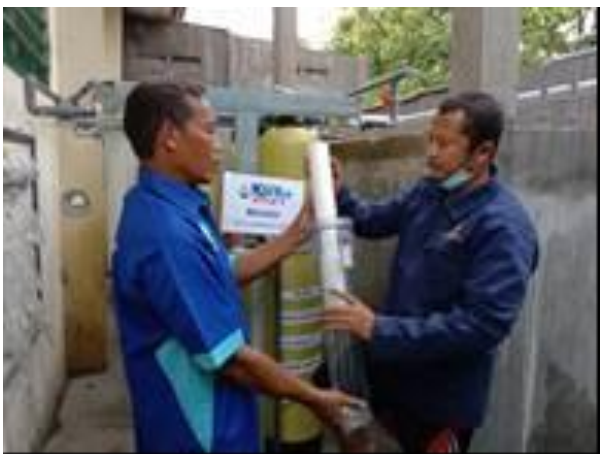

Gambar 6. Pencucian Housing Filter

2) Pemasangan Mikro Filter Pelanggan

Micro Filter di pasang pada konsumen / SR paling belakang, dimana kondisi kualitas airnya kurang bagus, sehingga perlu di pasang Micro Filter, hal ini dilakukan agar terjadi keseimbangan antara tingkat nilai bersiha iar di bak penampungan dengan kondisi air di lokasi pelanggan,sehingga kualitas air yang diterima pelanggan juga berhasil menjadi baik.

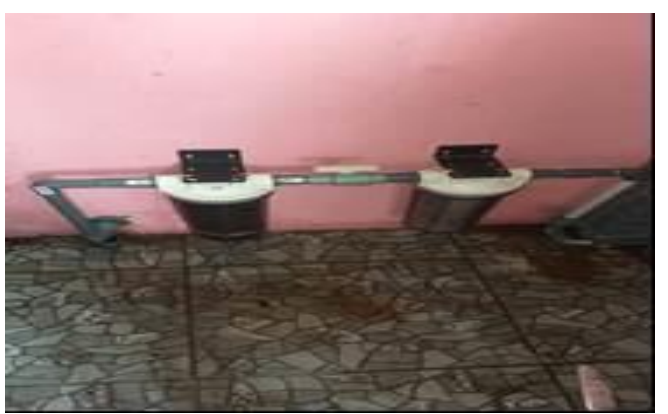

\section{Gambar 7. Mikro Filter Di Rumah} Pelanggan

\section{d. Pemberian fasilitas pendukung}

Fasilitas pendukung yang dimaksud dalam kegiatan ini berupa alat-alat yang digunakan untuk penjernihan air pada bak penampungan di lokasi Pamsimas Tirto Yoso, nah bebera bahan pendukung ini dapat disebutkan sebagai berikut :

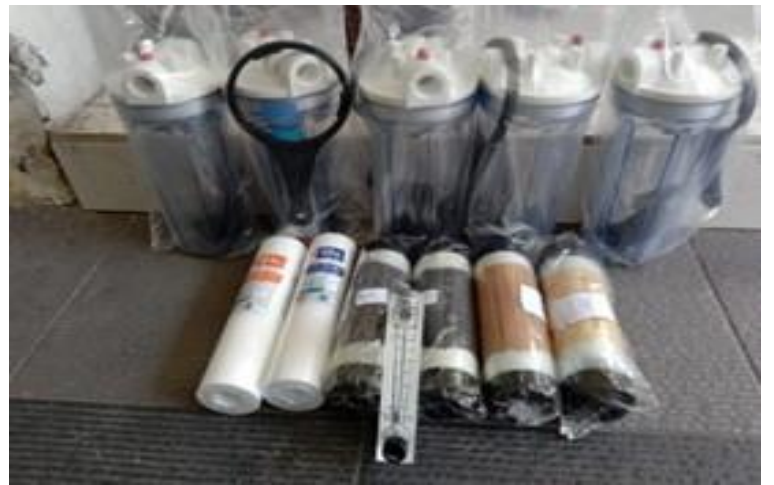

Gambar 8. Sedimen Poly propilen

1) Sidemen poly propilen. Mikro Filter berfungsi menyaring kandungan lumpur, pasir, tanah, sehingga menghasilkan air yang jernih. Ukuran dari 1 mikron sampai 10 mikron.

2) Ferrolite, berfungsi menghilangkan kandungan zat besi ( $\mathrm{Fe}$ ), Mangan (Ma), warna kuning pada air.

3) Manganse Green sand, Absorben zat besi dan mangan, dimana Reaksi dari $\mathrm{Fe}$ dan Mn mengahsilkan filtrat yang menghasilkan ferri-oksidasi dan mangan oksidasi yang tidak larut

4) Resin pengikat Ion / Kation dapat melakukan penukaran ion positip / negatip dari air.

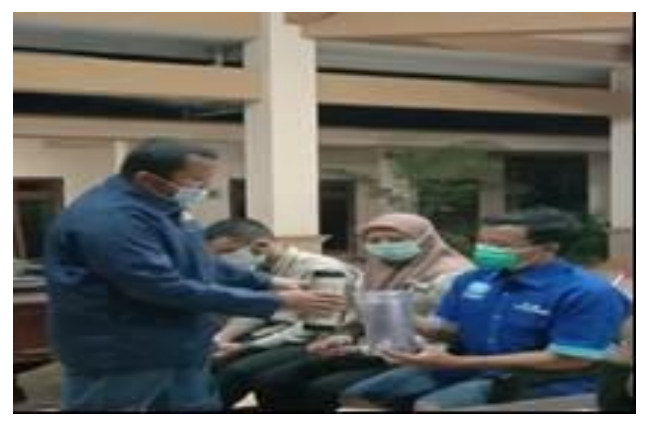

Gambar 9. Penyerahan alat pendukung

Berdasarkan hasil pelaksanaan kegiatan KKN-PPM di desa Junwangi Kecamatan Krian Kabupaten Sidoarjo tersebut, maka sebagai program utama yaitu pendampingan Teknologi Tepat Guna (TTG) berupa peralatan Mikro Filtrasi, dengan tahapantahapan yaitu : Sosialisasi penerapan TTG dihasilkan kegiatan penyuluhan dan edukasi tentang air bersih yaitu pelatihan kepada 
stakeholder ; Pengurus Pamsimas Tirto Yoso, Pelanggan air dan karang taruna desa Junwangi.

Pada tahapan pelatihan maintenance (perawatan) mahasiswa memberikan pelatihan langsung dilapangan berupa pembongkaran housing filter dan pembongkaran tabung FRP sedangkan pada tahapan pemberian fasilitas pendukung, mahasiswa memberikan beberapa peralatan baru yaitu berupa sedimen poly propilen. Ketiga program pendampingan TTG tersebut sangat bermanfaat bagi Pamsimas Tirto Yoso untuk kedepannya bisa menganggarkan pembiayaan lebih detail serta tata cara perawatan secara berkala.

\section{KESIMPULAN}

Pelaksanaan KKN-PPM Universitas PGRI Adi Buana Surabaya tahun 2020/2021 di Desa Junwangi Kecamatan Krian Kabupaten Sidoarjo, berjalan sesuai program, dimana tiga program kerja pelaksanaan pendampingan penerapan Teknologi Tepat Guna (TTG) dapat diterapkan secara baik, sehingga kegiatan ini mampu meningkatkan pengetahuan masyarakat terhadap kualitas air bersih, memberikan keahlian yang mendasar tentang perawatan (Maintenance) pada mikro filtrasi serta penambahan peralatan baru sebagai inventaris Pamsimas Tirto Yoso berupa alat sedimen poly propilen.

Saran yang dapat disampaikan oleh penulis bahwa diharapkan pelatihan dan sosialisasi yang diberikan kepada warga dan pengurus Pamsimas harus selalu diberikan secara kontinyu sehingga dalam perawatan dan operasional filtrasi Pamsimas dapat berjalan dengan baik. Diharapkan unit Filtrasi Pamsimas yang dihibahkan kepada Desa Junwangi dapat digunakan sebaik mungkin sehingga dapat dijadikan sebagai salah satu mata pencaharian masyarakat Junwangi.

\section{REFERENSI}

Masduqi, A., \& Assomadi, A. (2012). Operasi dan Proses Pengolahan Air. Surabaya: ITS Press.

Montgomery, J. (2005). Water Treatment Priciples and Design. USA: Johan Weley Inc.
Nurhayati, I. (2006). Desalinasi Air Payau dengan Membran Reverse Osmosi (RO) Tekanan Rendah. Enviromental Engineering RTL ITS Library, 50-58.

Purwoto, S., Purwanto, T., \& Hakim, L. (2015). Penjernihan Air Sungai dengan Perlakuan Koagulasi, Filtrasi, Absorbsi dan Pertukaran Ion. WAKTU, 45-53.

Putra, M. B. (2015). Gambaran Sumber Air Minum pada Penderita Diare di Desa Kintamani Kabupaten Bangli Bali. ISM , 47-52.

Qasim, S. R. (2000). Water Works Engineering Planning, Design and Operation. Texas: Chiang, Patel \& Yerby Inc.

Utomo, Y., \& Walujo, D. A. (2018). Penerapan Konstruk Technology Acceptance Model (TAM) pada Layanan Mobile Application di PDAM Surya Sembada Kota Surabaya. WAKTU, 39-48.

Waluyo, L. (2009). Mikrobiologi Lingkungan. Malang: UMM Press. 